\title{
The Effects of Exogenous Modulation on the Peripheral Nerve Regeneration after Injury and Primary Surgical Repair
}

\author{
Emilia Manole ${ }^{* 1,2}$, Alexandra Bastian ${ }^{2,3}$, Violeta Ristoiu ${ }^{4}$, Sabina Zurac ${ }^{2,3}$ and Monica Neagu ${ }^{1,2,4}$ \\ ${ }^{1}$ Victor Babes National Institute of Pathology, Bucharest, Romania
}

${ }^{2}$ Colentina Clinical Hospital, Bucharest, Romania

${ }^{3}$ Carol Davila University of Medicine and Pharmacy, Bucharest, Romania

${ }^{4}$ Faculty of Biology, University of Bucharest, Romania

Received: April 26, 2018; Published: May 08, 2018

*Corresponding author: Emilia Manole, Senior researcher Molecular Biology Laboratory “Victor Babes” National Institute of Pathology, 99-101 Splaiul Independentei, 050096, Bucharest, Romania Research Center, Colentina Clinical Hospital, 19-21 Stefan cel Mare Street, 020125, Bucharest, Romania

\begin{abstract}
Peripheral nerve injury can be surgically treated, but functional recovery is still unsatisfactory. That is why additional methods that can be applied after surgical repair and which modulate nerve regeneration are sought, this regeneration involving both the morphological recovery of the axon and the myelin sheath, but also the functional, physiological recovery of the peripheral nerve. Thus, in recent years, experimental studies have been undertaken in vivo and in vitro, but also in clinical trials involving electric stimulation, low-level laser therapy and pharmacotherapy. But many of these attempts are not yet standardized and well established, although their effect on the anatomicalfunctional recovery of the peripheral nerve is indisputable. In this review we present a brief overview of the main results obtained in these researches in recent years.
\end{abstract}

Key words: Peripheral nerve injury; Electric stimulation; Low-level laser therapy; Pharmacotherapy

\section{Introduction}

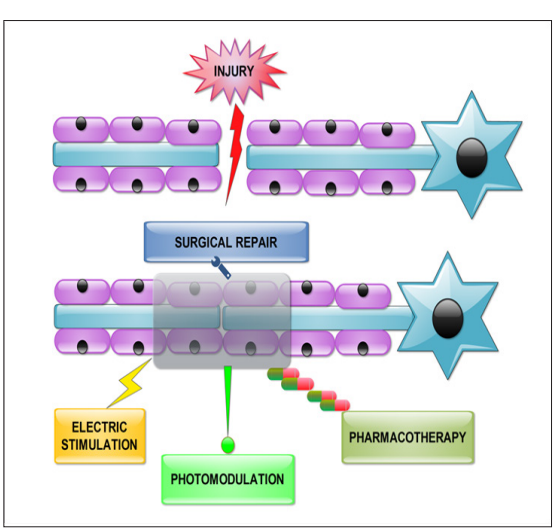

Figure 1: The methods proposed for exogenous modulation on peripheral nerve regeneration after injury and surgical repair: electric stimulation with low frequencies $(20 \mathrm{~Hz}$ or less), photo modulation with low-level laser $(50 \mathrm{~mW}, 15 \mathrm{~J})$ and pharmacotherapy (growth factors, pharmacological agents, hormones, bioproducts).
Regeneration of the peripheral nerve is a complex process that demands two actions: axonal sprout and demyelization. After the destruction of a portion of the peripheral nerve (by trauma, lesions or tumors), Wallerian degeneration of axon occurs, followed by a retrograde degeneration of the corresponding neurons in the spinal cord. Primary repair involves a surgical act for connection the two remaining nerve ends. Sometimes an autologous nerve graft is needed if the distance between the two nerve ends is too high [1]. The functional recovery after surgery is affected by inflammation, scar tissue formation, or the wrong direction of the axons that begin to regenerate. The axon rate of growth is slow, about $1 \mathrm{~mm} /$ day [2]. So, the recovery of nerve function is difficult and many times unsatisfactory. Modern surgical methods of peripheral nerve repair include the use of nanotubes from various synthetic materials [3] and the addition of stem cell to restore the Schwann cell population. These cells secrete neurotrophic and neurotropic factors that stimulate nerve regeneration $[4,5]$. All of these methods are widely described in the literature. The purpose of this review is to draw 
attention to some post-surgical methods that have been increasingly used in recent years to stimulate peripheral nerve regeneration and improve the recovery of nerve function after the surgical act has reached its goal. Such methods are electrical stimulation, low level laser therapy and pharmacotherapy. The methods proposed for exogenous modulation on injured peripheral nerve after surgical repair are depicted in Figure 1.

\section{Electric Stimulation}

The poor functional recovery of the peripheral nerve after injury and surgical repair makes demands for new strategies to stimulate its regeneration, like the electrical stimulation (ES). It is generally accepted that low frequencies, $20 \mathrm{~Hz}$ or less, can accelerate the actual recovery rate, findings that were proven in both animal models and in patients [6]. It has been demonstrated that a brief electrical stimulation has a good effect on accelerating axons outgrowth at the injury site $[7,8]$. Experimentally, in small rodents, a continuous low frequency $(20 \mathrm{~Hz})$ electrical stimulation was performed for 2 weeks on the proximal part of an injured nerve by axotomy and it was observed a regeneration of all axons of the femoral motor neurons over a distance of $25 \mathrm{~mm}$ after 3 weeks [7] Other studies have shown that an electrical stimulation for only 1 hour induces nerve regeneration on both motor and sensory nerves. ES promotes axonal growth along the lesion site and does not affect the axonal regeneration rate at the distal end of the injured nerve [9].

ES has been shown to be effective in the experimental chronic axotomy (when neurons stay for a long period without contact with the target organ) [10]. Other stimulation patterns have been tried with different durations and frequencies of ES [7-11] but it has been concluded that a procedure of $20 \mathrm{~Hz}$ once, for $30 \mathrm{~min}$ is enough to induce regeneration after nerve injury $[12,13]$. The mechanism of action is based on the cAMP-cyclic adenosine monophosphate increase [14-16] that accelerates the upregulation of neurotrophic factors and their receptors in neurons $[8,12,17]$ and Schwann cells [18-20] followed by the upregulation of cytoskeletal proteins, like tubulin and actin, and GAP-43 [9,17,21]. Similar findings were reported in in vitro studies on Schwann cell cultures [22,23], as well as from in vivo research after delayed repair of the nerve [10]. But the neurotrophic factors expression after ES is transient, lasting only few days [8]. The administration of androgens with ES sustains the regeneration mechanisms [12,24]. It has been shown that in patients, after carpal tunel release surgery, a brief $20 \mathrm{~Hz}$ ES for $1 \mathrm{~h}$ hour accelerates axonal growth and the reinnervation of the muscle after nerve damage [25]. Similar results were obtained for digital nerve transection [26].

\section{Phototherapy/Photomodulation}

The use of the low-level laser (LLL) for the treatment of peripheral nerve damage in experimental models has been shown to be effective in several recent studies. In an in vivo rat model with sciatic nerve crushing, it was found that laser phototherapy had an immediate protective effect in this incomplete peripheral nerve injury [27]. LLL treatment maintained a long-term functional activity, decreased scar tissue formation at the lesion site, decreased degeneration of the corresponding neurons in the spinal cord and significantly improved the axonal growth and myelination [28-31]. In an in vitro model, LLL therapy (with a $780 \mathrm{~nm}$ laser) was applied $1 \mathrm{~h}$ after cells seeding. The parameters used to apply the laser were generally the following: wavelength, 632.8-980 nm, power, $10-190 \mathrm{~mW}$, total energy, $0.15-90 \mathrm{~J}$, pulse or continuous wave in single or multiple points of application [32-36]. A model of a total, complete transection and anastomosis of the rat sciatic nerve, the $780 \mathrm{~nm}$ laser irradiation in different points (peripheral nerve and corresponding spinal cord), 15min/day, 21 days, resulted in a significant increase in the total number of axons, especially the large size ones, and in a better regeneration [37] compared to control animals. Similar results were obtained on the rat median nerve with end-to-side anastomosis [38].

In a model of rat segmental peripheral nerve loss with neurotube reconstrution, utilization of a LLL $(780 \mathrm{~nm})$ treatment $(15 \mathrm{~min} /$ day, 14 days) of nerve and spinal cord resulted in an acceleration of the axonal growth and regeneration [39]. In in vitro cell culture models, LLL accelerates cell migration, nerve cell growth, and fiber sprouting. One of these models used embryonic rat brain cells grown in micro carriers and embedded in neurogel [40]. In a pilot clinical trial in patients with a long-term incomplete peripheral nerve injury, LLL $(780 \mathrm{~nm})$ could progressively improve nerve function with a significant functional recovery [40,41]. Andreo et al. showed in 2017 that there are around 80 papers that document the acceleration of functional recovery due to the application of LLL therapy after peripheral nerve injury, as well as the modification of the morphological aspect of the nerve or the modulation of the expression of inflammatory cytokines and growth factors [32]. Most of these studies have used a laser power of up to $50 \mathrm{~mW}$ and a total energy of up to $15 \mathrm{~J}$ administered in multiple points. LLL in both the red and infrared spectra applied on injured peripheral nerve accelerated the functional recovery process.

Analyzing the morphological aspects of the nerve is important to see the results of LLL application [42]. These aspects refer to number and density of nerve fibers, mean diameter of axons with and without myelin sheath, thickness of the myelin sheath, area and perimeter of axons and fibers [43]. Another feature to be analysed is the cytokines and growth factors expression present to the injury site. The aim of LLL treatment is to diminish the pro-inflammatory cytokines presence and to enhance the growth factors expression, demonstrated in several studies [44-47]. However, it is necessary to standardize the LLL therapy protocol to improve the regeneration of the peripheral nerve following a lesion.

\section{Pharmacotherapy}

At present there is no pharmacological treatment available for repairing the injured peripheral nerve. But there are experimental studies that show that small molecules, such as peptides, growth factors or even hormones, have a positive effect on axonal regeneration and growth [48]. Growth factors like nerve growth factor (NGF) [49-51], brain-derived neurotrophic factor (BDNF) and ciliary neurotrophic factor (CNTF) [52-55], locally and systemically administered have contribute to axonal outgrowth, 
remyelination and functional recovery of injured peripheral nerve. Insulin growth factor-1(IGF-1), fibroblast growth factor (FGF) and glial-derived neurotrophic factor (GDNF), topically applied, have been shown to have an axonal regenerative effect and a better functional recovery result [56-59]. Neuregulin-1 (NRG1), which has a key role in axonal myelination, could be a good candidate for promoting remyelination after peripheral nerve trauma [60]. But the clinical management of growth factors still poses problems in terms of dosage/concentration and timing during treatment, their possible interaction with other growth factors, the side effects that may occur and even the method of administration. If all of these aspects are not well established, the effect may be the opposite $[61,62]$.

Another pharmacological method would be that of exogenous modulation of the expression of some endogenous growth factors. Another approach would be to find a method for growth factors controlled release or for the transplantation of specialized cells to produce them. Two pharmacological agents, $\mathrm{N}$-acetylcysteine (NAC) and acetyl-L-carnitine (ALCAR), experimentally shown to have a neuroprotective role and have been determined to be clinically safe [63-66]. Hormones are also studied as intervention factors in the pharmacological treatment of peripheral nerve damage. They could be neuroactive steroids, progesterone or allopreganolone, which interact with myelin proteins and influence the Schwann cells differentiation. Growth hormone and thyroid hormone have a beneficial effect on axonal myelination in experimental models $[67,68]$. Neurotransmitters like $\gamma$-aminobutiric acid (GABA), acetylcholine (Ach), adenosine triphosphate (ATP), with effect on neuronal-glial interaction are potentially candidates for studies on peripheral nerve repair [69,70]. Recently, plant extracts such as curcumin have been shown to have a beneficial effect on regeneration of injured peripheral nerve, on an animal model, reducing apoptosis, promoting myelination, regeneration and functional recovery of it.

\section{Conclusion}

After a surgical intervention to repair the nerve and a possible application of stem cells to the lesion site to induce Schwann cell regeneration and the activation of neurotrophic factors, there is a need for various exogenous interventions to improve both nerve regeneration and functional recovery that is still unsatisfactory in today's conditions. Recent data provided by biomedical literature show that acute and short ES application after primary surgery has good clinical applicability and induces axonal regeneration, increasing the possibility of functional recovery in various types of peripheral nerve injury. LLL therapy has demonstrated that it is a viable phototherapeutic way to improve recovery of peripheral nerve after injury. It has been shown to have positive effects on nerve regeneration using either infrared or red light. There is a need to standardize LLL parameters for a therapeutical protocol for peripheral nerve regeneration after injury.

Pharmacotherapy is also a beneficial intervention, but again, there is no standardization in this area, and the application of some bioproducts, small molecules, growth factors, hormones and others must be done with great care, not just the quantity but the dynamics of administration having a crucial importance. Otherwise, not only will not achieve the desired effect, but it can even get the opposite. Peripheral nerve repair is a multiple-approach process, combining surgical techniques with the other methods, some of them shown above. In the future, mathematical modeling and in silico models could be useful in understanding the cellular and molecular processes which occur in this pathology to adopt a better repair strategy.

\section{Aknowledgements}

Supported from Project PN-III-P1-1.2-PCCDI-2017-0782 (REGMED).

\section{References}

1. Millesi H (2007) Bridging defects: autologous nerve grafts. . In: Millesi H., Schmidhammer R. (eds) How to Improve the Results of Peripheral Nerve Surgery. Acta Neurochirurgica Supplementum 100: 37-38.

2. Fu SY, Gordon T (1997) The cellular and molecular basis of peripheral nerve regeneration. Mol Neurobiol 14(1-2): 67-116.

3. Pabari A, Lloyd-Hughes H, Seifalian AM, Mosahebi A (2014) Nerve conduits for peripheral nerve surgery. Plas Reconstr Surg 133(6): 14201430.

4. Faroni A, Terenghi G, Reid AJ (2013) Adipose-derived stem cells and nerve regeneration: promises and pitfalls. Int Rev Neurobiol 108: 121136.

5. Faroni A, Smith RJ, Reid AJ (2014) Adipose derived stem cells and nerve regeneration. Neural Regen Res 9(14): 1341-1346.

6. Gordon T, Sulaiman OAR, Ladak A (2009) Electrical stimulation for improving nerve regeneration: where do we stand? Int RevNeurobiol 87: 433-444.

7. Brushart TM, Hoffman PN, Royall RM, Murinson BB, Witzel C, et al. (2002) Electrical stimulation promotes motoneuron regeneration without increasing its speed or conditioning the neuron. J Neurosci 22(15): 6631-6638.

8. Al-Majed AA, Neumann CM, Brushart TM, Gordon T (2000) Brief electrical stimulation promotes the speed and accuracy of motor axonal regeneration. J Neurosci 20(7): 2602-2608.

9. Geremia NM, Gordon T, Brushart TM, Al-Majed AA, Verge VM (2007) Electrical stimulation promotes sensory neuron regeneration and growth-associated gene expression. Exp Neurol 205(2): 347-359.

10. Elzinga K, Tyreman N, Ladak A, Savaryn B, Olson J, et al. (2015) Brief electrical stimulation improves nerve regeneration after delayed repair in Sprague Dawley rats. Exp Neurol 269: 142-153.

11. Brushart TM, Jari R, Verge V, Rohde C, Gordon T (2005) Electrical stimulation restores the specificity of sensory axon regeneration. Exp Neurol 194(1): 221-229.

12. Sharma N, Marzo SJ, Jones KJ, Foecking EM (2010) Electrical stimulation and testosterone differentially enhance expression of regenerationassociated genes. Exp Neurol 223(1): 183-191.

13. Foecking EM, Fargo KN, Coughlin LM, Kim JT, Marzo SJ, et al. (2012) Single session of brief electrical stimulation immediately following crush injury enhances functional recovery of rat facial nerve. J Rehabil Res Dev 49(3): 451-458.

14. Udina E, Furey M, Busch S, Silver J, Gordon T, et al. (2008) Electrical stimulation of intact peripheral sensory axons in rats promotes outgrowth of their central projections. ExpNeurol 210(1): 238-247.

15. Aglah C, Gordon T, Posse De Chaves EI (2008) cAMP promotes neurite 
outgrowth and extension through protein kinase A but independently of Erk activation in cultured rat motoneurons. Neuropharmacology 55(1): 8-17.

16. Gordon T, Udina E, Verge VM, de Chaves EI (2009) Brief electrical stimulation accelerates axon regeneration in the peripheral nervous system and promotes sensory axon regeneration in the central nervous system. Motor Control 13(4): 412-441.

17. Al-Majed AA, Brushart TM, Gordon T (2000) Electrical stimulation accelerates and increases expression of BDNF and trkB mRNA in regenerating rat femoral motoneurons. Eur J Neurosci 12(12): 43814390 .

18. Huang J, Ye Z, Hu X, Lu L, Luo Z (2010) Electrical stimulation induces calcium-dependent release of NGF from cultured Schwann cells. Glia 58(5): 622-631.

19. Koppes AN, Zaccor NW, Rivet CJ, Williams LA, Piselli JM, et al. (2014) Neurite outgrowth on electrospun PLLA fibers is enhanced by exogenous electrical stimulation. J Neural Eng 11(4): 046002.

20. Wan L, Zhang S, Xia R, Ding W (2010) Short-term low-frequency electrical stimulation enhanced remyelination of injured peripheral nerves by inducing the promyelination effect of brain-derived neurotrophic factor on Schwann cell polarization. J Neurosci Res 88(12): 2578-2587.

21. Al-Majed AA, Tam SL, Gordon T (2004) Electrical stimulation accelerates and enhances expression of regeneration-associated genes in regenerating rat femoral motoneurons. Cell Mol Neurobiol 24(3): 379402.

22. Koppes AN, Nordberg AL, Paolillo GM, Goodsell NM, Darwish HA, et al. (2014) Electrical stimulation of Schwann cells promotes sustained increases in neurite outgrowth. Tissue Eng Part A 20(3-4): 494-506.

23. Koppes AN, Seggio AM, Thompson DM (2011) Neurite outgrowth is significantly increased by the simultaneous presentation of Schwann cells and moderate exogenous electric fields. J Neural Eng 8(4): 046023.

24. Sharma N, Moeller CW, Marzo SJ, Jones KJ, Foecking EM (2010) Combinatorial treatments enhance recovery following facial nerve crush. Laryngoscope 120(8): 1523-1530.

25. Gordon T, Amirjani N, Edwards DC, Chan KM (2010) Brief post-surgical electrical stimulation accelerates axon regeneration and muscle reinnervation without affecting the functional measures in carpal tunnel syndrome patients. Exp Neurol 223(1): 192-202.

26. Wong JN, Olson JL, Morhart MJ, Chan KM (2015) Electrical stimulation enhances sensory recovery: a randomized control trial. Ann Neurol 77(6): 996-1006

27. Rochkind S, Nissan,M, Lubart R, Avram J, Bartal A (1988) The in vivo nerve response to direct low-energy laser irradiation. Acta Neurochir 94(1-2): 74-77.

28. Rochkind S, Barr-Nea L, Razon N, Bartal,A, Schwartz M (1987) Stimulatory effect of He-Ne laser low-dose laser on injured sciatic nerves of rats. Neurosurgery 20(6): 843-847.

29. Rochkind S, Nissan M, Barr-Nea L, Schwartz M, Bartal A (1987) Response of peripheral nerve to He-Ne laser: Experimental studies. Lasers Surg Med 7(5): 441-443.

30. Rochkind S, Barr-Nea L, Volger I (1990) Spinal cord response to laser treatment of injured peripheral nerve. Spine 15(1): 6-10.

31. Rochkind S, Nissan M, Alon M, Shamir M, Salame K (2001) Effects of laser irradiation on the spinal cord for the regeneration of crushed peripheral nerves in rats. Lasers Surg Med 28(3): 216-219.

32. Andreo L, Soldera CB, Ribeiro BG, de Matos PRV, Bussadori SK, Fernandes KPS, et al. (2017) Effects of photobiomodulation on experimental models of peripheral nerve injury. Lasers Med Sci 32 (9): 2155-2165.

33. Belchior AC, dos Reis FA, Nicolau RA, Silva IS, Pereira DM, et al. (2009) Influence of laser $(660 \mathrm{~nm})$ on functional recovery of the sciatic nerve in rats following crushing lesion. Lasers Med Sci 24(6): 893-899.

34. Takhtfooladi MA, Jahanbakhsh F, Takhtfooladi HA, Yousefi K, Allahverdi A (2015) Effect of low-level laser therapy $(685 \mathrm{~nm}, 3 \mathrm{~J} / \mathrm{cm} 2)$ on functional recovery of the sciatic nerve in rats following crushing lesion. Lasers Med Sci 30(3): 1047-1052.

35. Masoumipoor M, Jameie SB, Janzadeh A, Nasirinezhad F, Soleimani M, et al. (2014) Effects of 660- and 980-nm low-level laser therapy on neuropathic pain relief following chronic constriction injury in rat sciatic nerve. Lasers Med Sci 29(5): 1593-1598.

36. Sousa FF, Andraus RA, Barbieri CH, Mazzer N (2009) Influence of laser radiation in nerve regeneration in different treatments sites. Acta Ortop Bras 17(6): 331-335.

37. Shamir M H, Rochkind S, Sandbank J, Alon M (2001) Double-blind randomized study evaluating regeneration of the rat transected sciatic nerve after suturing and postoperative low power laser treatment. J Reconstruct Microsurg 17(2): 133-138.

38. Gigo-Benato D, Geuna S, de Castro Rodrigues A, Tos P, Fornaro M, et al. (2004) Low-power laser biostimulation enhances nerve repair after end-to-side neurorrhaphy: A doubleblind randomized study in the rat median nerve model. Laser Med Sci 19(1): 57-65.

39. Rochkind S, Leider-Trejo L, Nissan M, Shamir M, Kharenko O, et al. (2007) Efficacy of 780-nm laser phototherapy on peripheral nerve regeneration after neurotube reconstruction procedure (double-blind randomized study). Photomed Laser Surg 25(3): 137-143.

40. Rochkind S, El-Ani D, Hayun T, Nevo Z, Shahar A (2009) Increase of neuronal sprouting and migration using 780-nm laser phototherapy as procedure for cell therapy. Lasers Surg 41(4): 277-281.

41. Rochkind S, Drory V, Alon M, Nissan M, Ouaknine G E (2007) Laser phototherapy $(780 \mathrm{~nm})$, a new modality in treatment of long-term incomplete peripheral nerve injury: a randomized double-blind placebocontrolled study. Photomed Laser Surg 25(5): 436-442.

42. Raimondo S, Fornaro M, Di Scipio F, Ronchi G, Giacobini-Robecchi MG, Geuna S, et al. (2009) Chapter 5: Methods and protocols in peripheral nerve regeneration experimental research: part II-morphological techniques. Int Rev Neurobiol 87: 81-103.

43. Geuna S, Raimondo S, Ronchi G, Di Scipio F, Tos P, et al. (2009) Chapter 3: Histology of the peripheral nerve and chances occurring during nerve regeneration. Int Rev Neurobiol 87: 27-46.

44. Wang CZ, Chen YJ, Wang YH, Yeh ML, Huang MH, et al. (2014) Low-level laser irradiation improves functional recovery and nerve regeneration in sciatic nerve crush rat injury model. PLoS One 9(8): e103348.

45. Chen YJ, WangYH, Wang CZ, HoML, Kuo PL, et al. (2014) Effect of low level laser therapy on chronic compression of the dorsal root ganglion. PLoS One 9(3): e89894.

46. Gomes LE, Dalmarco EM, André ES (2012) The brain-derived neurotrophic factor, nerve growth factor, neurotrophin-3, and induced nitric oxide synthase expression after low-level laser therapy in an axonotmesis experimental model. Photomed Laser Surg 30(11): 642647.

47. Alcântara CC, Gigo-Benato D, Salvini TF, Oliveira AL, Anders JJ, et al. (2013) Effect of low-level laser therapy (LLLT) on acute neural recovery and inflammation-related gene expression after crush injury in rat sciatic nerve. Lasers Surg Med 45(4): 246-252.

48. Faroni A, Mobasseri SA, Kingham PJ, Reid AJ (2015) Peripheral nerve regeneration: experimental strategies and future perspectives. Adv Drug Deliv Rev 82-83: 160-167.

49. Santos X, Rodrigo J, Hontanilla B, Bilbao G (1998) Evaluation of peripheral nerve regeneration by nerve growth factor locally administered with a novel system. J Neurosci Methods 85(1): 119-127.

50. Rich KM, Alexander TD, Pryor JC, Hollowell JP (1989) Nerve growth 
factor enhances regeneration through silicone chambers. Exp Neurol 105(2): 162-170.

51. Derby A, Engleman VW, Frierdich GE, Neises G, Rapp SR, et al. (1993) Nerve growth factor facilitates regeneration across nerve gaps: morphological and behavioral studies in rat sciatic nerve. Exp Neurol 119(2): 176-191.

52. Utley DS, Lewin SL, Cheng ET, Verity AN, Sierra D, et al. (1996) Brainderived neurotrophic factor and collagen tubulization enhance functional recovery after peripheral nerve transection and repair. Arch Otolaryngol Head Neck Surg 122(4): 407-413.

53. Sahenk Z, Seharaseyon J, Mendell JR (1994) CNTF potentiates peripheral nerve regeneration. Brain Res 655(1-2): 246-250.

54. Lewin SL, Utley DS, Cheng ET, Verity AN, Terris DJ (1997) Simultaneous treatment with BDNF and CNTF after peripheral nerve transection and repair enhances rate of functional recovery compared with BDNF treatment alone. Laryngoscope 107(7): 992-999.

55. Ho PR, Coan GM, Cheng ET, Niell C, Tarn DM, et al. (1998) Repair with collagen tubules linked with brain-derived neurotrophic factor and ciliary neurotrophic factor in a rat sciatic nerve injury model. Arch Otolaryngol Head Neck Surg 124(7): 761-766.

56. Kanje M, Skottner A, Sjoberg J, Lundborg G (1989) Insulin-like growth factor I (IGF-I) stimulates regeneration of the rat sciatic nerve. Brain Res 486(2): 396-398.

57. Fujimoto E, Mizoguchi A, Hanada K, Yajima M, Ide C (1997) Basic fibroblast growth factor promotes extension of regenerating axons of peripheral nerve. In vivo experiments using a Schwann cell basal lamina tube model. J Neurocytol 26(8): 511-528.

58. Fine EG, Decosterd I, Papaloizos M, Zurn AD, Aebischer P (2002) GDNF and NGF released by synthetic guidance channels support sciatic nerve regeneration across a long gap. Eur J NeuroSci 15(4): 589-601.

59. Danielsen N, Pettmann B, Vahlsing HL, Manthorpe M, Varon S (1988) Fibroblast growth factor effects on peripheral nerve regeneration in a silicone chamber model. J Neurosci Res 20(3): 320-330.

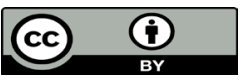

This work is licensed under Creative Commons Attribution 4.0 License

Submission Link: https://biomedres.us/submit-manuscript.php
60. La Marca R, Cerri F, Horiuchi K, Bachi A, Feltri ML, et al. (2011) TACE (ADAM17) inhibits Schwann cell myelination. Nat Neurosci 14(7): 857865.

61. McArthur JC, Yiannoutsos C, Simpson DM, Adornato BT, Singer EJ, et al. (2000) A phase II trial of nerve growth factor for sensory neuropathy associated with HIV infection. AIDS Clinical Trials Group Team 291. Neurology 54(5): 1080-1088.

62. Novikova LN, Novikov LN, Kellerth JO (2000) BDNF abolishes the survival effect of NT-3 in axotomized Clarke neurons of adult rats. J Comp Neurol 428(4): 671-680.

63. Reid AJ, Shawcross SG, Hamilton AE, Wiberg M, Terenghi G (2009) $\mathrm{N}$-acetylcysteine alters apoptotic gene expression in axotomised primary sensory afferent subpopulations. Neurosci Res 65(2): 148-155.

64. Hart AM, Terenghi G, Kellerth J0, Wiberg M (2004) Sensory neuroprotection, mitochondrial preservation, and therapeutic potential of N-acetyl-cysteine after nerve injury. Neuroscience 125(1): 91-101.

65. Wilson AD, Hart A, Brannstrom T, Wiberg M, Terenghi G (2003) Primary sensory neuronal rescue with systemic acetyl-L-carnitine following peripheral axotomy. A dose-response analysis. Br J Plast Surg 56(8): 732-739.

66. Zhang CG, Welin D, Novikov L, Kellerth JO, Wiberg M, et al. (2005) Motorneuron protection by $\mathrm{N}$-acetyl-cysteine after ventral root avulsion and ventral rhizotomy. Br J Plast Surg 58(6): 765-773.

67. Mercier G, Turque N, Schumacher M (2001) Rapid effects of triiodothyronine on immediate-early gene expression in Schwann cells. Glia 35(2): 81-89.

68. Devesa P, Gelabert M, Gonzlez-Mosquera T, Gallego R, Relova JL, et al. (2012) Growth hormone treatment enhances the functional recovery of sciatic nerves after transection and repair. Muscle Nerve 45(3): 385-392.

69. Magnaghi V, Procacci P, Tata AM (2009) Chapter 15: Novel pharmacological approaches to Schwann cells as neuroprotective agents for peripheral nerve regeneration. Int Rev Neurobiol 87: 295-315.

70. Zhao Z, Li X, Li Q (2017) Curcumin accelerates the repair of sciatic nerve

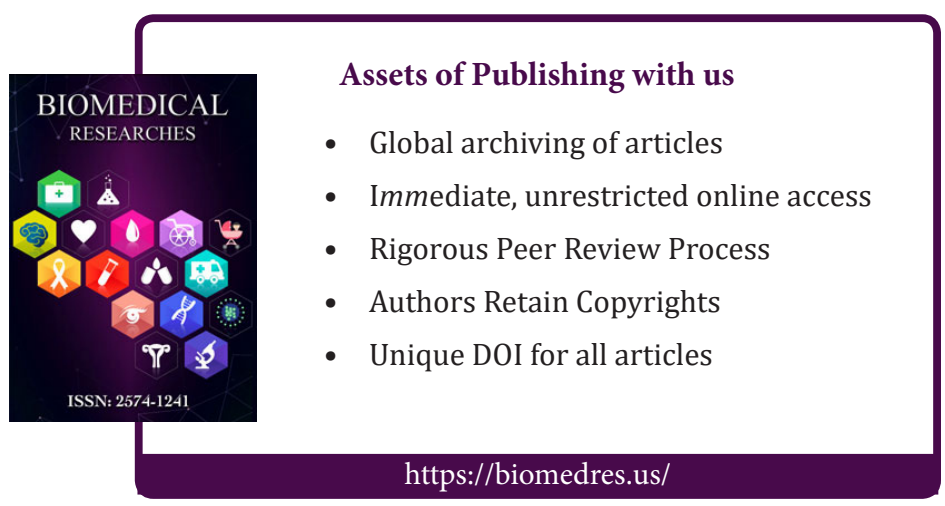

